Revista de la red interuniversitaria de estudios sobre las literaturas rioplatenses contemporáneas en Francia

$22 \mid 2021$

¿Cómo se cuenta una vida? El retorno de lo biográfico en la literatura rioplatense contemporánea

\title{
Una revolución propia. Idea Vilariño y su poesía política.
}

Une révolution à elle seule. Idea Vilariño et sa poésie politique.

A revolution of her own. Idea Vilariño's political poetry.

\section{Ana Inés Larre Borges}

\section{OpenEdition}

\section{Journals}

Edición electrónica

URL: http://journals.openedition.org/lirico/10539

DOI: 10.4000/lirico.10539

ISSN: 2262-8339

Editor

Réseau interuniversitaire d'étude des littératures contemporaines du Río de la Plata

Referencia electrónica

Ana Inés Larre Borges, «Una revolución propia. Idea Vilariño y su poesía política.», Cuadernos LIRICO

[En línea], 22 | 2021, Publicado el 12 marzo 2021, consultado el 16 marzo 2021. URL: http:// journals.openedition.org/lirico/10539; DOl: https://doi.org/10.4000/lirico.10539

Este documento fue generado automáticamente el 16 marzo 2021.

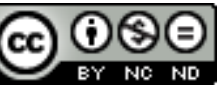

Cuadernos LIRICO está distribuido bajo una Licencia Creative Commons Atribución-NoComercialSinDerivar 4.0 Internacional. 


\title{
Una revolución propia. Idea Vilariño y su poesía política.
}

\author{
Une révolution à elle seule. Idea Vilariño et sa poésie politique. \\ A revolution of her own. Idea Vilariño's political poetry.
}

Ana Inés Larre Borges

1 A diferencia de otros intelectuales de su generación, Idea Vilariño no despertó a la conciencia política por efecto de la revolución cubana. Hija de un padre "poeta y anarquista", según gustó repetir, creció junto a sus hermanos en una tradición de izquierda muy minoritaria en aquel Uruguay de dos divisas de la primera mitad del siglo XX. En una "memoria de infancia" que escribió como preámbulo a su diario, recuerda que cuando el golpe de estado de Terra, en 1933, salían junto a su joven tía Inés por la noche a pasar panfletos contra la dictadura por debajo de las puertas (2013: 77). En su casa eran votantes de Emilio Frugoni, fundador del Partido socialista uruguayo, abogado, poeta y legislador que representó por largo tiempo una corriente minoritaria en el Uruguay bipartidista de blancos y colorados.

2 Acaso ese origen haya incidido en la manera que adoptó después al escribir poesía política. Idea sostuvo una actitud intransigente y una posición ideológica radical que la alineó en los años sesenta junto al Movimiento de Liberación Nacional Tupamaros, pero publicó escasos poemas políticos y los escribió desde una subjetividad infrecuente en el género. Lejos de la épica, su poesía comprometida es, si fuese posible nombrarla así, intimista. Es verdad que compuso encendidas canciones de lucha que en las voces de Los Olimareños, Daniel Viglietti, y otras figuras de la canción protesta, se convirtieron en himnos revolucionarios, pero actuó de modo diferente con su poesía comprometida. Los poemas de Pobre mundo y otros que quedaron inéditos o fuera de su Poesía completa, tienen la dureza de sus convicciones, pero parten por lo general de una experiencia personal, doméstica incluso, y se enuncian desde una interioridad precisa, anclada en lo biográfico.

3 Quiero explorar esa singular asimetría que conecta lo más público de su producción literaria con su historia personal. Pensar esos poemas en diálogo con el contexto 
histórico en que fueron creados, las circunstancias en que fueron escritos y en relación con la tramitación de su otra obra.

\section{La muchachita que dio el buen/mal paso. Un comienzo complicado}

"A Guatemala" es el primer poema político de Idea. Lo escribió como respuesta al derrocamiento de Jacobo Árbenz en 1954 y para denunciar la injerencia norteamericana en América Latina. El golpe contra Árbenz acabó por consumarse, con la ya indiscutible participación de la Agencia Central de Inteligencia estadounidense, el 27 de junio de 1954. Idea estaba entonces en Estocolmo, adonde había viajado para acompañar a su hermana Alma, que iba a ser operada en Suecia. Anota en su diario su desesperación "de tener que adivinar en los títulos de los diarios suecos lo que pasaba" $(16.07 .1954)^{1}$ y en la misma entrada escribe: "Poema a Guatemala", forma habitual de registro de la escritura de un poema. Desde Europa lo envió al semanario Marcha, que se había ocupado del caso Guatemala desde tiempo atrás; primero con atención entusiasta hacia proceso de reformas sociales llevadas a cabo por el gobierno de Árbenz, y luego en la denuncia de la injerencia extranjera y en la defensa de la asediada república. A pesar de esos antecedentes, Vilariño tuvo que insistir para que el poema fuese publicado. Emir Rodríguez Monegal, Jefe de Literarias del semanario, cofundador y codirector entonces con Vilariño de la revista Número, artífice de la cimentación de su prestigio poético y amigo personal, se mostraba reticente. Se publicó, finalmente, el 8 de octubre de 1954.

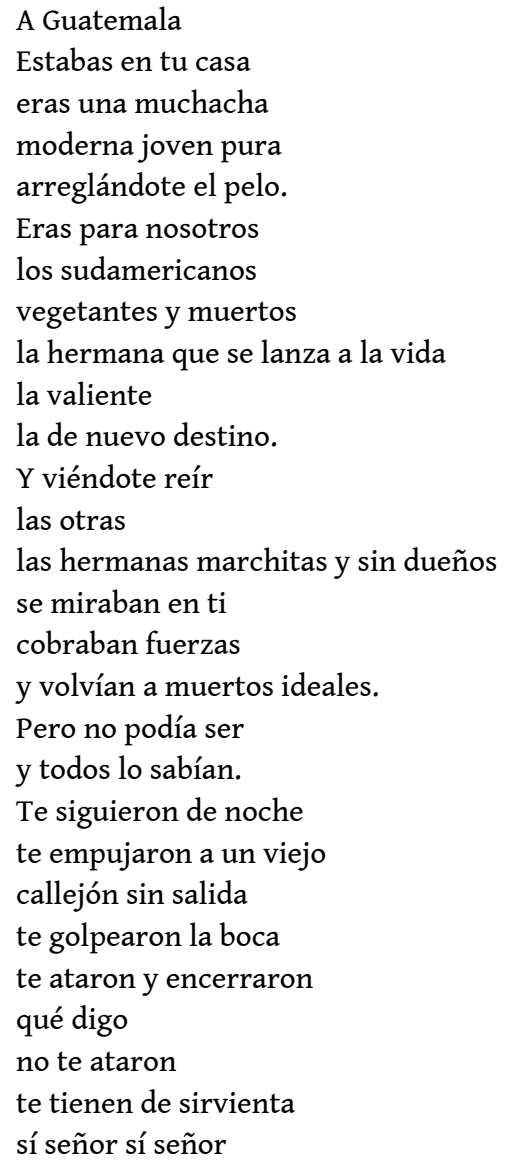




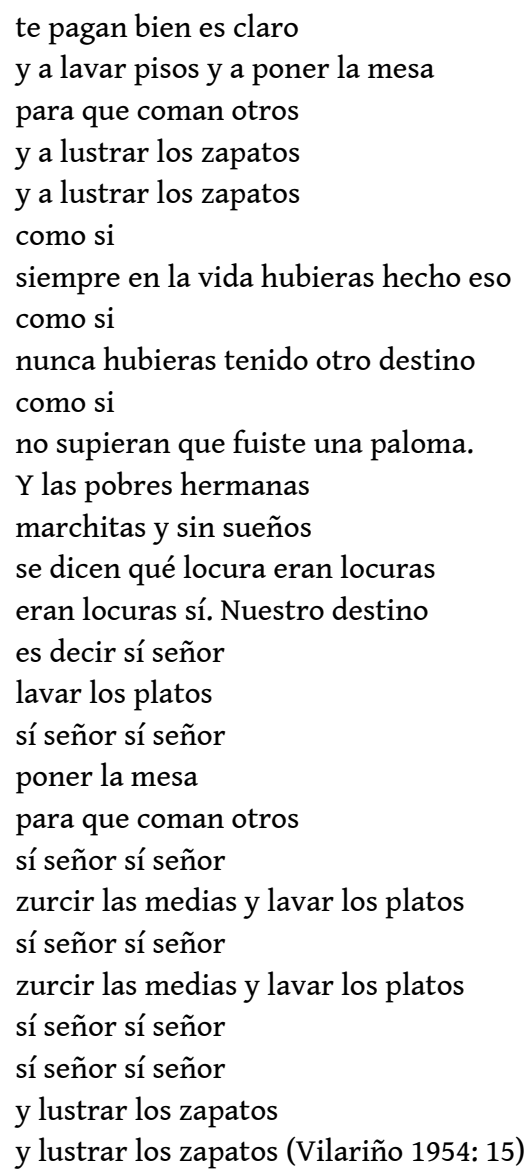

5 A través de una metáfora audaz que asimilaba a la frágil república enfrentada a un imperio con una joven golpeada, humillada y obligada al servicio, el poema reeditaba el mito de David contra Goliat, pero en clave femenina y en derrota. Una heroína más soñadora que valiente, cuya caída es mezquina, mermada por la rutina reiterada del esclavo que los versos remedan en su repetición mecánica. Fuera de las resistencias de Rodríguez Monegal, el único registro que quedó de la recepción del poema fue un suelto anónimo que publicó el diario oficialista El Día. Se tituló "Cursilería”:

Alguien que ha dado en poner en malos versos ripiosos, vaya a saber qué sentimiento de frustración interior dedica una poesía a Guatemala. Y para expresar su lamentable simbolismo poético, compara a ese país bajo el régimen comunista, con la muchacha emancipada a quien miran sus hermanas con temor y con lástima, por el triste fin que la espera. Cuando ese fin llega, las hermanas, que representan a las restantes repúblicas americanas, entonan una cursi queja plañidera, de la que dan ejemplo los siguientes "versos": “... y las pobres hermanas / marchitas y sin sueños...". Difícilmente alcanzable, tal extremo de cursilería revela infortunadamente que hay gentes que se titulan intelectuales y se sienten dotadas para la producción intelectual, a las que mueven sentimientos oscuros, cuya liberación por intermedio de la poesía, da lugar a que se atente contra el buen gusto y los sentimientos normales del pueblo, mediante expresiones innobles impropias del vivir saludable y libre de que se disfruta en el país. ("Cursilería" 1954: 8)

El anónimo, que despliega un repertorio bastante completo de las tácticas de la injuria, evitaba nombrar a la autora echando mano de un procedimiento corriente en un país de cercanías donde no era preciso explicitar ni la identidad de la poeta ni la del medio que la publicó para que el agravio alcanzara su meta. Si la confrontación era ideológica, el suelto centraba su ataque en un argumento misógino clásico: el ridículo. La frase final 
con su convencional apelación al "buen gusto", la "normalidad" y "la salud del pueblo" blanquea una ideología que pasa por la política, pero va más allá y explica la desproporcionada animosidad.

Debe reconocerse, sin embargo, que el ataque fue más sutil de lo que estas tosquedades dejan adivinar a quien ignore el contexto en el que fueron esgrimidas. La acusación de "cursilería" enrostraba a Marcha una falta que el propio semanario había convertido en pecado capital a través de la prédica sofisticada y soberbia de su sección cultural. "Marcha es, sobre todo en sus proverbiales páginas de crítica literaria o cinematográfica, ejemplo del terror a la cursilería", acusó ese mismo año un jovencísimo Juan Fló (2019: 111)². Lejos de ser un rival ideológico o periodístico, Fló era, a sus 24 años, un asiduo lector de Marcha, y su crítica formaba parte de un texto que envió al concurso sobre "Los problemas de la juventud en Uruguay", convocado por el propio semanario. El texto de Fló inauguraba un ataque que luego haría suyo la generación del sesenta respecto a los del 45: la autocomplacencia crítica, la pusilanimidad frente a la vida, la incapacidad de acción. A esa generación crítica y a la figura de Rodríguez Monegal, juez y gendarme de las letras y, en la ocasión, parte del jurado, Fló les recriminó:

La triste moda de la anticursilería que, indiscriminadamente, agrede todo esfuerzo de relación con los temas del hombre, que coarta dentro de nosotros mismos la posibilidad de sufrir impúdicamente, que nos arrastra a otorgar simpatía e indulgencia a toda pretendida obra de arte en la que no aparezcan ni por asomo las malas palabras tocadas de trascendencia. (110)

Marcha publicó los textos de los ganadores con una introducción de Carlos Real de Azúa, quien, como jurado, había defendido al impugnador con éxito modesto pero suficiente para asegurarle una publicación que hizo algún ruido en el ambiente intelectual. No es improbable que ese ruido haya alcanzado al autor del brulote de El Día. El ataque al poema fue también un ataque por extensión a Marcha y, por intención, a Emir Rodríguez Monegal. La estocada del anónimo fue diestra. O estaba al tanto de los reparos del crítico o los dedujo bien, porque no es improbable que Emir compartiese un juicio parecido sobre "A Guatemala". En 1948 había publicado en esas mismas páginas "La poesía de Idea", un artículo extenso y consagratorio, y desde entonces no dejó pasar oportunidad para cimentar el prestigio de su amiga escribiendo él o propiciando otros comentarios, publicando sus poemas en las páginas de Número y de Marcha (Torres 2014). Es instructivo volver a aquel primer artículo y notar que, al nombrar a Idea, Emir se refiere siempre a "el poeta", universalizando, como anota Alicia Torres (2014: 307), el masculino. Fue actitud generalizada entre las poetas del 45 el rechazo a definirse como "poetisas" so pena de incurrir en el omnipresente pecado, y ese tabú se hizo hegemónico en el Uruguay. El masculino usado (no exclusivamente) por Rodríguez Monegal, que lo reitera en otro artículo de $1956^{3}$, exageraba ese prurito hasta lo ininteligible, aunque, hay que decirlo, no fue óbice para que escribiese las primeras lecturas sensibles de sus poemas. También había dosis concentradas de virilidad en las virtudes que celebraba aquel primer ensayo donde se descubre: "a un auténtico poeta: fuerte y personal, maduro en su juventud, intenso y firme. Un poeta de raíz, capaz de organizar severas estructuras, pero capaz, además, de ofrecer, en total desnudez, su ardiente voz" (1948: 14). Frente a estos elogios de lo severo, raigal, fuerte y firme, la metáfora femenina a la que recurre Idea para hacer un poema político debió provocarle al menos decepción. "El Poema de Guatemala no me gustó como suyo. ¿Me entiende?", expresaba de modo afable y discreto en una carta que envía a Suecia el 23 de setiembre. 
Casi un mes después envía otra, para anunciarle con buen humor que: "Guatemala y usted prevalecieron. El poema salió (sin erratas espero) la semana pasada”. Además de trasmitirle el entusiasmo que despertó en los otros dos poetas de Número, Mario Benedetti y Sarandy Cabrera, Emir matiza su juicio: "Yo no sé qué decirle. Impreso me parece mejor, creo que gana con la relectura. Pero, creo también que su poesía de Ud. está en otra parte"4.

La amistad entre Idea y Emir acabó de deteriorarse por distanciamientos políticos en tiempos de creciente polarización ideológica, pero teniendo en cuenta sus juicios, no parece improbable que la metáfora de la muchachita abusada le disgustase tanto como la incursión de Vilariño en la poesía comprometida, un género con el que nunca comulgó. La transgresión era doble y pronto regresaría de manera más desnuda.

Dos años después, en una escena célebre de su biografía, Idea renuncia a Marcha a raíz de la censura que su director, Carlos Quijano, impuso al poema "El amor" por el verso "un pañuelo con sangre semen lágrimas". El conflicto, que incluyó una pelea con Monegal, ha sido referido por distintas fuentes y en varias ocasiones, también en detalle a través del testimonio de la propia Idea en el documental que lleva su nombre (Jacob 1997). Me interesa rescatar unas palabras que registró en su diario cuando reclamó a Emir su derecho de explicar a los lectores las razones de su renuncia: "le recordé que nunca le había pedido que me publicara algo salvo el poema de Guatemala" (30.10.1956). Esta temprana conexión entre los casos de "A Guatemala" y "El amor" guarda un sentido. Ocurridos a un año de distancia, la contigüidad invita a percibirlos como transgresiones impremeditadas a reglas no escritas de un orden establecido. En 1956, el episodio de censura de "El amor" había puesto en juego otra osadía, la del sexo, pero los prejuicios que enfrentó no eran muy diferentes. El castigo, el altísimo precio, fue la autoexclusión de Vilariño de las páginas de Marcha. La reacción que suscitó el verso de "El amor" debió desconcertar a Idea que, según muestran los poemas que quedaron inéditos en su archivo, hacía ya más de una década escribía poesía erótica con audacias semánticas equivalentes a la que escandalizó al director de $M a r c h a^{5}$. En perspectiva y en comparación con otras figuras de su generación, Idea Vilariño había alcanzado una autonomía bastante excepcional entre las mujeres del medio siglo. En la exacta mitad de la refrenada década, desafiaba sus convenciones desde una conquistada seguridad. Vilariño acordaba con las insurgencias que proponían en el otro hemisferio escritoras como Simone de Beauvoir o Mary McCarthy y padecía el sino de las protagonistas de sus ficciones. Vivió como quiso, pero recibió, en el modo asordinado de aquellos tiempos, lo que tocaba a los disidentes del modelo de normalidad saludable, por decirlo en la semántica de quien salió al cruce de su primer poema político. “¿Hasta cuándo tendremos que tolerar los coitos de la señorita Vilariño?". En la callada microhistoria que en Uruguay circula durante un tiempo en susurros y chismes y se disuelve luego como lo que nunca existió, esa frase atribuida a Quijano en ocasión de la censura a "El amor", se pierde para la historia oficial, oculta por el tupido velo de una urbanidad de aldea. Idea habría de regresar a las páginas de Marcha a principios de la década del setenta "por razones de militancia política", según dejó asentado en una cronología de su vida ${ }^{6}$, y nunca pasó cuentas por el incidente a Quijano, a quien en una entrevista tardía, incluyó en el selecto grupo de mentores de su generación: "Éramos algo que tenía que pasar y que estaba cómodo entre el rigor de Torres, el de Ayestarán, el de Carlitos Real, el de Quijano" (Albistur 2020: 334). Las dos rebeldías de Idea Vilariño quedaron sueltas, aisladas, incomunicadas hasta muy 
recientemente, cuando algunas lecturas, como la de Teresa Johansson (2014: 280), conciliaron sus reivindicaciones políticas con las de género. "A Guatemala" había atizado reacciones fuertes que, sin embargo, quedaron invisibilizadas. Vilariño no colaboró para que el episodio se integrase a su trayectoria como hizo en el caso de "El amor". Un error resiliente impuso la versión de que Idea habría quedado insegura del valor de su primer poema político tras su conflictiva recepción y no lo publicó por eso en la primera edición de Pobre mundo (Rocca 2012: 190; Johansson 2014: 283). No fue así, "A Guatemala" integró aquella edición inaugural en 1966 (p. 20-21) y también la de Poesía, primera edición abarcativa de su obra, que le publicó Ángel Rama en 1970. Fue bastante después, a partir de su exclusión de la segunda edición de Pobre mundo en 1988, que el poema quedó fuera de su repertorio hasta 2002, en que lo recuperó para su Poesía completa. Habría que buscar razones más matizadas que expliquen esa ausencia. Hasta hoy existen detractores de este poema que se empeña en mostrar dentro y fuera de la literatura, en sus versos y en sus ecos, la trama doble de una rebeldía radical aunque discreta que modeló la obra y la vida de Idea.

\section{Una revolución propia}

11 "A Guatemala" inauguraba su poesía política, aunque no su compromiso. La ideología familiar heredada se había transformado en militancia activa. Un par de años antes de la publicación del poema, Idea integró la Comisión directiva y la de propaganda en el Movimiento de Resistencia contra el Tratado Militar con Estados Unidos, puestos a los que renuncia por desacuerdos con la creciente injerencia del Partido Comunista ${ }^{7}$. Esa militancia no era ajena al nexo especial que se dio entonces entre Guatemala y Uruguay donde las simpatías por el proceso social y democrático de la república centroamericana alcanzaban al gobierno colegiado presidido por Luis Batlle Berres y a varios sectores del espectro político. En el contexto de la Guerra Fría, Uruguay fue tierra de asilo para los que buscaban ponerse a salvo de las persecuciones que se desataron después del golpe. En Montevideo coincidieron dos expresidentes guatemaltecos: Juan José Arévalo -afín y cercano al presidente Luis Batlle Berres, y colaborador del semanario de Quijano-, y su sucesor derrocado, Juan Jacobo Árbenz, que llegó en 1957. También el líder comunista José Manuel Fortuny entró con nombre falso y sostuvo reuniones con comunistas locales (García Ferreira 2010). Recuperar el impacto que significó la invasión norteamericana en Latinoamérica y reconocer la conexión uruguaya ilumina las circunstancias que alentaron la escritura del primer poema político de Vilariño. Un año antes, había escrito "Andar diciendo muerte", en el que expresaba una contradicción que la iba a acompañar por el resto de su vida: la dificultad de conciliar su nihilismo con el impulso por participar en la historia y sus combates. Decía el poema:

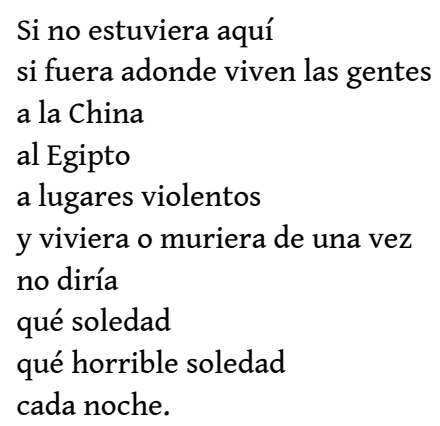


Me callaría a qué andar hablando a qué

andar diciendo muerte

cuando la vida estalla

andar diciendo muerte

cuando vaya a encontrarla

a volver una esquina. (Vilariño 2020a: 100)

"Andar diciendo muerte" era expresión de un conflicto que perduró, pero a la vez mutó a lo largo de su vida. La contradicción que enuncia no fue equilibrada ni constante, una pendular alternancia entre el escepticismo absoluto y el sueño de la revolución acabó por dibujar un itinerario irregular, con periodos de intensidad y de silencio, en inevitable diálogo con coyunturas históricas que afectaron y alteraron la creación de esta poesía comprometida. La historia editorial del poema ilustra ese proceso. Escrito en 1953, se publicó dos años después en la primera edición de Nocturnos, pero fue retirado en la segunda, de 1963. Lo recuperó en Poesía, de 1970 (p. 60), pero con un cambio relevante: quitó la mención a "la China, al Egipto" y la sustituyó por la más universal: "a lugares violentos donde se vive o muere". En 1970 la violencia había dejado de ser lejana o exótica. En una entrevista que Mario Benedetti hizo a Vilariño en ocasión, precisamente, de la publicación de Poesía, ella celebra "el derrumbe del mito arcádico" y los cambios que eso produjo. Benedetti pregunta, entonces, qué había cambiado para ella; Idea respondió con otra pregunta: “QQuién se suicida, quién se retira del mundo, quién lleva un diario íntimo, quién ahora?" (2007: 60-67). ${ }^{8}$ Con la retórica cortante de muchos de sus poemas, asumía una transformación que se reflejó en su obra, aunque pese a la autoinfligida irrisión, su pesimismo y su misantropía no desaparecieron. Cohabitaron con la vehemencia revolucionaria, con resultados fecundos muchas veces y con las tensiones inherentes a las uniones imposibles.

En los años sesenta, en sintonía con el proyecto revolucionario que se instaló en América Latina y en Uruguay, se intensificó la escritura de poemas políticos. Si se revisa la cronología de la edición definitiva del apartado II de Pobre mundo, seis de diez poemas fueron escritos entre 1967 y 1970; si se mira los "Cuadernos" donde Idea copió en orden cronológico, según fue su costumbre, los poemas de estos años ${ }^{9}$ la concentración de poesía política se multiplica, dado que están también allí las canciones y varios poemas que no recogió en su Poesía completa.

La poesía de Vilariño se fue radicalizando a medida que se agudizaron los conflictos y se expandió en el continente la lucha armada. Sus versos y canciones se cargaron de una emoción endurecida que busca expresar violencia, dañar con la palabra.

En algunos poemas esa ira puede volverse desdén por la poesía. "Agradecimiento", que participa de ese modo particular de hacer poesía política desde la subjetividad más expuesta, lleva un epígrafe que declara: "Esto, que de poema tiene solo la forma", y pasa luego a agradecer al enemigo por las fotos de los cadáveres de guerrilleros muertos que llegan de Bolivia y de Vietnam enmarcadas por "textos falaces" ${ }^{10}$. Hacia fines de los años sesenta y comienzo de los setenta la poesía de Idea no teme ser prosaica y se mezcla con el periodismo. No solo a través de su circulación - publicó esos poemas en Marcha y los dedicó a periodistas amigos-, sino porque los creó a partir de noticias, fotos, documentos. La realidad reclamaba atención y la poeta le dio la bienvenida. En ese contexto, menos que una disculpa, la prevención del acápite era un alarde. La valoración de las vidas ofrendadas, motivo clásico de la épica, tiene en este poema su contraparte en el desprecio por las vidas ahorradas, preservadas de los 
neutrales. Establece tres categorías de vida: la del héroe que da la vida, la de los enemigos y sicarios que también mueren y la de los muchos:

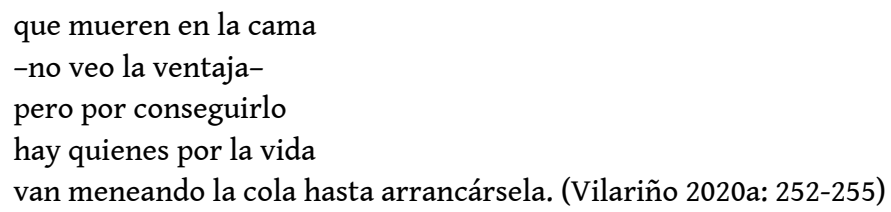

Es sorprendente que esta radical ferocidad sea compatible con la intimidad que sostiene los poemas. Muchas veces esa subjetividad llega a partir de la puesta en escena de la enunciación. "Agradecimiento", "Digo que no murió", "Solo para decirlo" y "Por fin", cuatro de los diez poemas políticos de Poesía completa, son poemas performáticos, cuyo sentido depende de un decir, sea bajo la especie del desafío, la negación, el agradecer irónico o, en dos ocasiones, el insulto; son las palabras las que actúan. Ese recurso también está en un poema que quedó fuera de su obra reunida, "Pedro", de 1967, dedicado a un tupamaro. Idea lo publicó como cierre de Poesía, en 1970, junto a "Digo que no murió", bajo un título de la misma cepa: "No quiero". Aunque existen indicios de que "Pedro" pudo haber sido una relación sentimental de la autora, la intimidad del poema se juega menos en esa posibilidad que en la pura enunciación de la intolerancia que le produce tan solo imaginar su tortura o su muerte: "Pedro pedro / que no te toquen / pedro", "que no sea ahora / pedro / que respires aún / pises aún la tierra..."; y que, después de considerar que la muerte pueda ser parte de un destino revolucionario, termina en un ruego, regateando con la muerte: "no quiero que te maten / todavía" (Vilariño 1988: 55).

17 Otro de los poemas que quedó fuera de su obra completa, "Eras portorriqueño...", un poema largo, datado en abril de 1968, sobre un joven que va a pelear y a morir a Vietnam, es casi una carta. Casi porque, aunque la revelación de su muerte llega al final como un golpe de efecto, el poema lo sabe desde el inicio y guarda la huella de ese conocimiento en la imperfección del pretendido diálogo, en un encuentro fugaz en la intimidad de un vuelo compartido:

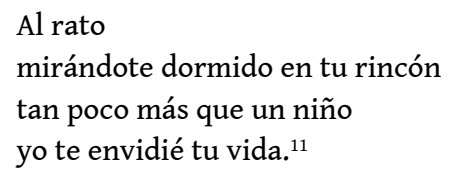

La circunstancia que dio origen al poema estuvo seguramente en un viaje a Cuba, en tiempos en que para trasladarse de Montevideo a La Habana había que realizar, a causa del bloqueo, un desvío por los países del Este, pero el poema no precisa decir la circunstancia de ese encuentro, la necesidad de esclarecer es de otra índole. Es la denuncia inherente a toda poesía política la que obliga a dejar a la vista el artificio. El poema termina con lo que seguramente estuvo en su origen: la noticia de la muerte de José Varona. La confesión personal se convierte entonces en un tributo al héroe y el poema cumple su función ejemplarizante.

\section{Decir no. El poema al Che}

En la entrevista de 1994, Idea define sus poemas políticos como "respuestas" a sucesos de la historia (Albistur 2020: 347). En más de una ocasión ha quedado registrado el pasaje de la noticia recibida al poema. Llama la atención, desde una perspectiva actual, el retraso con que llegaban esas noticias, su confusa trasmisión y demora. En 
consecuencia, se instaura un espacio de incertidumbre y se despliega una anagnórisis cargada de impaciencia, anhelo y miedo, que los versos recogen y aprovechan. La urgencia que manifestaba Idea por descifrar en el opaco alfabeto sueco la invasión a Guatemala, alcanza acaso su epítome en el suspenso que se vivió cuando la muerte del Che.

Pocos hechos provocaron en América Latina un impacto parecido al que produjo la muerte de Ernesto Guevara en 1967. Su captura y ejecución en el paisaje pobre de La Higuerita boliviana ocurrió en sincronía con la culminación de procesos históricos que contribuyeron a amplificar el duelo y el sentido de esa muerte. Las páginas de Marchaentonces en su momento de mayor influencia- testimonian bien la atónita recepción de la noticia y el fervor que encendió esa muerte. También revelan que "Digo que no murió", el poema de Idea que, ya desde el título, se centra en la negación trascendente de la muerte del héroe, nace de un desconocimiento real y una resistencia a aceptar su desaparición que fue histórica y compartida por muchos, aferrados a la esperanza de que se tratase de una maniobra de desinformación enemiga. El 14 de octubre de 1967, el Che llevaba muerto cinco días, pero el titular de tapa de Marcha todavía preguntaba: “¿Está muerto el Che Guevara?”. Carlos María Gutiérrez, periodista estrella y escritor que unos años antes había logrado entrevistarlo en Sierra Maestra, se refería aún a su "presunta muerte": "Veinticuatro horas antes de cerrar esta edición, las noticias cablegráficas y los periódicos argentinos ofrecen una colección de informaciones sobre la presunta muerte de Ernesto Guevara que admite sin demasiado esfuerzo la duda legítima" (Gutiérrez 1967: 16).

21 Se desconfiaba de la veracidad de la noticia y se sospechaba de maniobras de la CIA y el Pentágono para minar la moral de los movimientos revolucionarios latinoamericanos. Se dudaba con los mismos argumentos que regresan en los versos de Idea.

"Digo que no murió" se publicó recién el 10 de noviembre de 1967, un mes después del asesinato de Guevara. El poema tiene un aliento universal que desafía a la muerte, pero ancla de modo sorprendentemente concreto en aquella incertidumbre agónica que se vivió durante los días en que las fuentes que anunciaban su muerte eran las del enemigo. Es posible que Idea haya empezado a escribir el poema antes de que se diese una confirmación definitiva, pero fue su decisión no corregir esa ignorancia $\mathrm{y}$, en cambio, asimilarla al poema:

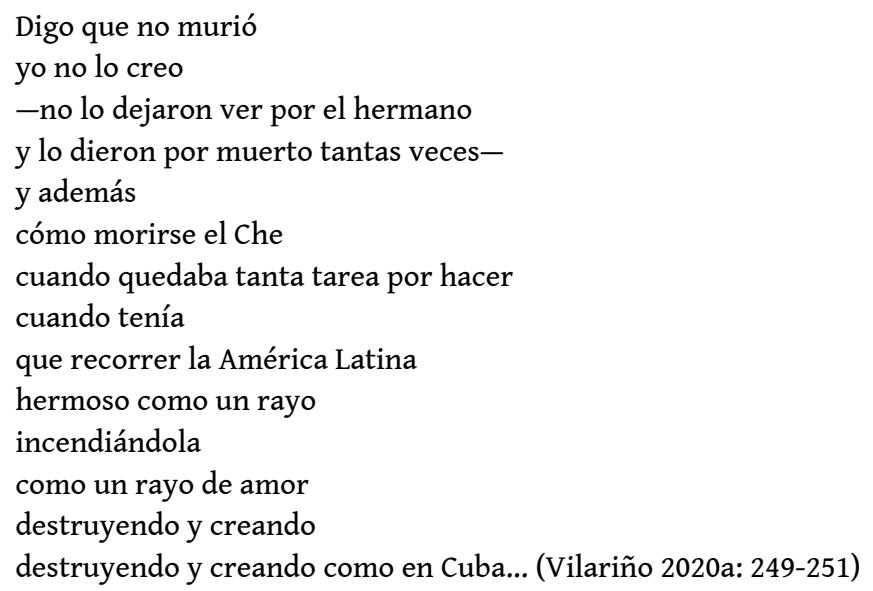

23 Si el imperioso primer verso revierte la duda en un desafío olímpico y el segundo hace de la muerte del héroe un asunto personal, los que llegan después - los versos 3 y $4-$ regresan a la dimensión terrena tal como se discutió y argumentó en aquellos días. Es 
casi escandalosa la fidelidad de este poema a los argumentos de Gutiérrez en Marcha. Escribía este en el ya citado artículo: "No menos significativo es que el doctor Roberto Guevara, hermano del Che, haya viajado infructuosamente a Santa Cruz - por avión acompañado de tres periodistas bonaerenses- para ver el cadáver" (Gutiérrez 1967: 17). A lo que replica Idea en sus versos: "no lo dejaron ver por el hermano", seguido en la primera versión por un verso más prosaico - “y tantas otras cosas"- que después corrigió, según puede verse en la copia manuscrita del Cuaderno 17, páginas 6 y 7, en Princeton ${ }^{12}$.

Cuando una semana después, Marcha salió con la foto invertida del cadáver del Che en tapa, su director, Carlos Quijano, dio explicaciones a los lectores: "En un primer momento todos desechamos de plano la noticia, después la noticia fue cobrando cuerpo, Fidel pronunció su discurso para calificar de dolorosamente cierta la información procedente de Bolivia" (Quijano 1967: 18). El resto del número fue un gran homenaje al héroe: "Guevara, libertador de América Latina". Poemas de Mario Benedetti, de Amanda Berenguer, textos de Eduardo Galeano y Arturo Ardao. En la contratapa, un collage sobre la famosa fotografía canónica de Korda hecha por el dibujante de Marcha, Blankito, con una leyenda que coincide con un sentimiento general y con el poema de Vilariño: "El Che ha muerto, vive el Che".

Idea comulgó con aquel clamor continental y lo expresó en su poema mezclando la ancestral tradición de la épica con la crónica de las noticias. "Digo que no murió" afirma los mitos de inmortalidad y ubicuidad del héroe y los combina con cada registro de su hora final -fotografías, noticias, declaraciones desde La Habana, nombres revelados- que fueron el modo en que se vivió colectivamente la larga muerte del Che. Guarda la duda y la incredulidad histórica y la ensambla con datos que llegaron después, desde el reconocimiento de La Habana a la denuncia del responsable directo de esa muerte, al que dedica el vengativo final del poema:

Qué iba a morirse el che

qué va a morirse.

Pero esa foto atroz

aquella bota

cómo partía el alma aquella bota

la sucia bota y norteamericana

señalando la vida con desprecio.

No hay que creerlo. Hubo

tantas contradicciones

y lo dieron por muerto tantas veces.

Qué iba a morirse el Che.

Él nada menos

se iba a dejar cercar en ese valle

iba a salir a un claro

iba a quedarse

a estarse allí

a dejar

que le rompa las piernas la metralla.

Yo no voy a creerlo. Un día

un buen día dirán está en Brasil

o se alzará en Colombia o Venezuela

a ayudar

a ayudarnos

y ese día

una ola de amor americano 
moverá el continente

alzará al che de América.

No creo que murió

no puedo creerlo

y no voy a creerlo

aunque lo afirme el mismo Fidel Castro.

Pero amigos

hermanos no olvidarse

no olvidar nunca el rostro despreciado

el corazón más sucio que esa bota

ni la mano vendida

acordarse del rostro

de la mano

acordarse del nombre

hasta que llegue el día

y cuando llegue

cuando suene la hora

acordarse del nombre y de la cara

de ese teniente Prado. (Vilariño 2020a: 250-251)

De la incredulidad compartida toma la negación que se vuelve mandato ético y aleja al poema del duelo y la elegía para convertirlo en canto de lucha y de revancha. Un año después, para el aniversario del Che, vuelve a escribir un texto en Marcha, esta vez en prosa, una pieza rara y dura que tituló "Sin excusas, ni alivio, ni perdón" y que se enuncia, también, desde la intimidad:

Tengo junto a mi mesa de trabajo uno de sus retratos menos difundidos, tal vez el más hermoso. Y lo miro a menudo, mucho, me quedo mirándolo. A veces lo hago con intolerable dolor, con el duro sufrimiento del día en que me resigné a creerlo. Pero otras con rencor siento que me, que nos, ha traicionado, fallando, muriendo. (Vilariño 1968a: 31)

27 Es un texto que conecta directamente con el poema, porque lo alude y porque hubo además un largo duelo colectivo que sostuvo, y quizás acrecentó, la emoción. Su aliento está, sin embargo, lejos de "Digo que no murió"; es, en cambio, una concentración de la más impiadosa y amarga Vilariño que elige hablar de culpa y de culpables dentro de las filas revolucionarias. Sobre el final, podría decirse que bordea la retractación:

Yo no estoy muy segura, tampoco, de que morirse importe; tampoco estoy segura de que una revolución - los hombres-, pasado el tiempo, $-\mathrm{y}$ ni siquiera tanto tiempo-, no deba corromperse irremediablemente, volviendo vanos el desgarrado parto, el sufrimiento y la esperanza. Y su muerte; sus muertes. De manera que todo esto es bastante irracional. No lo veo muy claro y eso no me importa ni quiero justificarlo. Tal vez sea, es, reprobable. Pero es lo que siento, y no puedo, no sabría escribir, hacer, otra cosa que no sea afirmar amarga y apasionadamente, mirando sin cansancio su retrato, que no me perdono ni le perdono a nadie esto. (Ibíd.)

Era, tal vez, simplemente, el viejo nihilismo insobornable que regresaba por sus fueros. Pasada la ilusión revolucionaria, censurada la voz de los vencidos, la poesía política de Idea no desapareció, aunque mermó y supo ocultarse. Se la descubre dispersa en poemas como "Se cerraron las puertas" y "En el fondo del pozo", -son los números 36 y 37 de No-, ambos de 1975, en los que puede reconocerse un lacónico testimonio de la derrota y la tortura, también está en los versos inacabados que guardan los cuadernos de Princeton, donde ensaya la potente impotencia del insulto, como en "La puta que los parió..." de 1977, que evoca y redobla el furor de "Solo para decirlo" de 1970. En 1979, la revolución sandinista regaló a Idea la escritura del que sería el último poema político que publicó: "Por fin" (2020a: 259). "Nada más real que una fecha", supo decir Barthes, 
este poema "A Nicaragua" - tuvo ese título que es ahora su epígrafe- pone en juego toda la fuerza antirretórica de esta poesía: el insulto, la elipsis, los gestos mudos, la soledad, el ensimismamiento, luchan en la página hasta llegar a la realidad dichosa que "sucedió / por fin / hoy / diecinueve / del mes de julio del setenta y nueve" y, como antes, la tortura del Vietcong en "Con los brazos atados", también esta victoria se hace eterna en sus versos: los rebeldes entran, cada vez que alguien lee el poema, a una Managua liberada. Más allá de esos desplazamientos y de ese logro, cabe reconocer que, a la imposibilidad declarada en su prosa al Che, a su confesa escisión irreparable, debemos la indagación de algunas fronteras últimas de la poesía revolucionaria.

\section{BIBLIOGRAFÍA}

Albistur, Jorge, “Entre la pasión y el escepticismo", entrevista a Idea Vilariño, en Poesía completa, Montevideo, La Suplicante, 2020, p. 329-348.

Benedetti, Mario, “El amor y la muerte esas certezas”, entrevista a Idea Vilariño, en La vida escrita, Montevideo, Cal y Canto, 2007, p. 60-67.

“Cursilería”, El Día, 19 de octubre de 1954, p. 8.

Fló, Juan, "Problemas de la juventud en nuestro país", Revista de la Biblioteca Nacional, "Polémicas / Afinidades", Época 3, Año 11, n. 15, 2019, Montevideo, Biblioteca Nacional de Uruguay, p. 103-116. Introducción de Ana Inés Larre Borges.

García Ferreira, Roberto, “José Manuel Fortuny: un comunista clandestino en Montevideo, 1958”. Jornadas de Investigación de la Facultad de Ciencias Sociales. Montevideo, 13-15 de septiembre de 2010. Web. Consultado el 6 de abril de 2020.

Gutiérrez, Carlos María: "Un grito de guerra contra el imperialismo: Ernesto Che Guevara y su tarea ininterrumpible” Marcha, Montevideo, n. ${ }^{\circ}$ 1374, 14 de octubre de 1967, pp. 16 y 17.

Jacob, Mario, Idea (documental), 1997.

Johansson, M. Teresa, “Los sesenta de Idea Vilariño: poesía, política y canción”, Revista de la Biblioteca Nacional, “Idea”, Época 3, Año 6, n. 9, 2014, Montevideo, Biblioteca Nacional de Uruguay, p. 279-293.

Quijano, José Manuel, “El pensamiento vivo de Guevara”, Marcha, n. 1375, 20 de octubre de 1967, p. 18-22.

Rocca, Pablo, Revistas culturales del Río de la Plata. Diálogos y tensiones (1945-1960), Montevideo, CSIC, 2012.

Rodríguez Monegal, Emir: “Sobre la poesía de Idea”, Marcha, nº 458, 10 de diciembre de 1948, p. 14.

---, “El mundo poético de Idea Vilariño. La nueva poesía uruguaya (1945-1955)”, Marcha, no 824, 3 de agosto de1956, p. 21-22. 
Torres, Alicia, "Emir Rodríguez Monegal artífice de la entrada de Idea Vilariño al canon literario nacional”, Revista de la Biblioteca Nacional, “Idea”, Época 3, Año 6, n. 9 9, 2014, Montevideo, Biblioteca Nacional de Uruguay, p. 295-316.

Vilariño, Idea, “A Guatemala”, Marcha, nº 740, 8 de octubre de 1954, p. 15.

---, “Digo que no murió”, Marcha, nº 1378, 10 de noviembre de 1967, p. 27.

---, “Sin excusas, ni alivio, ni perdón”, Marcha, nº 1420, 11 de octubre de 1968, p. 31.

---, Poesía 1941-1967, Montevideo, Arca, 1970.

---, Pobre mundo, (2a. edición), Montevideo, Arca, 1988.

---, La vida escrita, Libro álbum. Montevideo, Academia Nacional de Letras -Cal y Canto, 2007.

---, Poesía completa, Montevideo, La suplicante, 2020a. Prólogo de Luis Gregorich. Edición y notas de Ana Inés Larre Borges

---, Poemas recobrados (1931-1944), Montevideo, Biblioteca Nacional de Uruguay, 2020 b.

\section{NOTAS}

1. Todas las referencias a los diarios corresponden a la Agenda 1949-1955 [Agenda perpetua de tapa negra, manuscrita en fibra negra, roja y verde] que se encuentra en la carpeta de "Diarios" en la "Colección Idea Vilariño" de la Biblioteca Nacional de Uruguay. Se referencian por la fecha de entrada consignada en el documento.

2. Citamos el texto "Problemas de la juventud en nuestro país" según la reedición incluida en el número 15 de la Revista de la Biblioteca Nacional.

3. Véase en la Bibliografía: Rodrígez Monegal 1956.

4. Carta de Emir Rodríguez Monegal, datada en Montevideo, 23 de setiembre de 1954. En "Correspondencia R", Colección Idea Vilariño, Archivo Literario de la Biblioteca Nacional.

5. De 1943 son "Canto" y "El hombre que me ama", rescatados recientemente. Escribe en el último: “...Así es que nos amamos. / Cuando abraza la muerte le hace estrechar más hondo / cuando entra la muerte eyacular más alto" (Vilariño 2020b: 335).

6. Aunque no lleva su firma, la cronología a su obra completa fue supervisada y corregida por la poeta. Véase Poesía completa, Montevideo, Cal y Canto, 2006, p. 324.

7. En la Agenda 1949-1955 (véase nota 1) está copiada la carta de su renuncia fechada en noviembre de 1952. En mayo del siguiente año, anota que el Tratado Militar va al Parlamento y lamenta que la destrucción del Movimiento impida "hacer algo".

8. En 1994, lejos de la ilusión revolucionaria, en otra entrevista clave, se referirá al origen de sus contradicciones: "una personalidad partida en dos entre la pasión y el escepticismo, entre la obligación moral de hacer algo -diversas formas de militancia- y el descreimiento último" (Albistur 2020: 347-348).

9. Desde 2019 los "Cuadernos" donde Idea pasó sus poemas fueron puestos en línea con acceso libre por la Universidad de Princeton, a cuyo archivo fueron vendidos junto a otros documentos de menor interés. Solo se libraron al público los Cuadernos de poesía, "Notebooks \& Agendas". Al Cuaderno 14 (según numeración de Vilariño) o "Poemas 1967" se accede por el siguiente enlace: https://findingaids.princeton.edu/collections/C1567/c12

10. “Agradecimiento" se publicó por primera vez en Marcha n. ${ }^{\circ} 1041$ 30, el 10 de mayo de 1968, con el mismo acápite que guarda su edición definitiva y con una dedicatoria que no guarda: “a Pedro". 
11. Existen dos registros de este poema en dos cuadernos de la Colección 1567, Idea Vilariño's Papers del archivo Princeton. Uno en Cuaderno 14, pp. 61 y 62 (https://findingaids.princeton.edu/ collections/C1567/c9) y otro en Cuaderno 17 p. 11 y 12 (https://findingaids.princeton.edu/ collections/C1567/c12).

12. Ver el manuscrito en línea, Archivo Princeton, Colección 1567, Idea Vilariño's Papers: (https://findingaids.princeton.edu/collections/C1567/c12).

\section{RESÚMENES}

Idea Vilariño tuvo posiciones políticas radicales y una militancia activa cercana a movimientos revolucionarios, pero escribió pocos poemas políticos y lo hizo desde una marcada subjetividad. Este trabajo busca explorar el anclaje biográfico de esa zona de su poesía y su relación con el contexto histórico y las circunstancias en que fueron escritos esos poemas. Atiende también a la tensión entre su nihilismo existencial y su impulso a la acción revolucionaria y su reflejo en la poesía comprometida que creó.

Idea Vilariño avait des positions politiques radicales et un militantisme actif proche des mouvements révolutionnaires, mais elle écrivait peu de poèmes politiques et le faisait à partir d'une subjectivité marquée. Cet article cherche à explorer l'ancrage biographique de ce domaine de sa poésie et sa relation avec le contexte historique et les circonstances dans lesquelles ces poèmes ont été écrits. Il aborde également la tension entre son nihilisme existentiel et son désir d'action révolutionnaire et le reflet de cette tension dans sa poésie engagée.

Idea Vilariño had radical political ideas and was a left activist in her life, but wrote relatively few political poems, and did it in an extremely personal and intimate way. This essay explores the biographical roots of her political poetry, related to the historical context and the circumstances in which her poems were written. It also addresses the tension between her existential nihilism and her drive for revolutionary action in her political poems.

\section{ÍNDICE}

Palabras claves: Idea Vilariño, poesía política, biografía, periodismo, nihilismo, revolución. Mots-clés: Idea Vilariño, poésie politique, biographie, journalisme, nihilisme, révolution. Keywords: Idea Vilariño, political poetry, biography, journalism, nihilism, revolution.

\section{AUTOR}

\section{ANA INÉS LARRE BORGES}

Departamento de Investigaciones

Biblioteca Nacional de Uruguay

anaineslarreborges@gmail.com 